\title{
EDITORIAL
}

\section{Harmonising spirometry education with HERMES: training a new generation of qualified spirometry practitioners across Europe}

\author{
I. Steenbruggen*, S. Mitchell ${ }^{\#}$, T. Severin\# ${ }^{\#}$ P. Palange ${ }^{\star}$ and B.G. Cooper ${ }^{+}$on behalf of the Spirometry \\ HERMES Task Force
}

64 undreds of millions of people of all ages suffer from preventable chronic respiratory diseases and respiratory allergies in all countries of the world.... accounting for 4 million deaths annually" [1].

The considerable toll of respiratory diseases in terms of quality of life, disability of patients and indeed premature death [2] underlines the importance of spirometry in the detection and monitoring during the management of respiratory disease. Yet, in the past two decades, there have been specific concerns of under-utilisation in screening [3], lack of training [4] and misdiagnosis based on inaccurate results $[5,6]$ which only serve to document the inadequacies in spirometry practice not only within Europe but on a world-wide scale.

An abundance of reports [2-8] has propelled quality issues in the practice of spirometry to centre stage and consequently introduced a number of quality improvement strategies. High-quality spirometry relies on three key determinants: 1) documented guidelines in spirometry, 2) access to quality spirometers, and finally, 3) trained and qualified spirometry practitioners [9]. To some degree, the ERS/ATS guidelines in standardisation of spirometry [10] and availability of affordable spirometers across medical settings have directly addressed these first two factors. Further efforts implemented in the US by NIOSH (National Institute for Occupational Safety and Health), in several European countries, as well as across New Zealand and Australia through ANZSRS (Australian and New Zealand Society of Respiratory Science) have produced comprehensive training structures with supporting documents and certification criteria to endorse health professionals with a qualification to practice high-quality spirometry. There is some evidence which consistently shows that competence in spirometry is the key to quality services [7, 11, 12], but access to such training and assessment is relatively limited. Adopting HERMES (Harmonising Education in Respiratory Medicine for European Specialists) as a framework, this article presents the

\footnotetext{
*Pulmonary Laboratory 8000, Zwolle, The Netherlands. " ERS Headquarters, Lausanne, Switzerland. 'Dipartimento Medicina Clinica, Rome, Italy. ${ }^{+}$Lung Investigation Unit, Birmingham, UK.

CORRESPONDENCE: I. Steenbruggen, Pulmonary Laboratory, Isala klinieken loc WI C2, P0 box 10500, 8000 GM, Zwolle, the Netherlands; i.steenbruggen@isala.nl; B.G. Cooper, Lung Investigation Unit, University Hospital Birmingham, B15 2TH, Birmingham, UK; brendan.cooper@ uhb.nhs.uk
}

ambitious task to follow this intricate path and implement quality standards in the practice of spirometry across all of Europe.

\section{HERMES}

Within the HERMES framework, the various Task Forces for each project aim to produce uniform documents and activities to the highest standard, thus offering measurable criteria for medical training institutions [13-17]. Improvement in patient care and quality of life for patients with respiratory disease is the ultimate goal. A survey conducted within ERS emphasised the current gap in the content, duration and quality of spirometry training across Europe, the result of which acted as a springboard to launch the European Spirometry Driving Licence HERMES project at the annual ERS Congress 2008.

Deviating from previous HERMES initiatives, the Spirometry HERMES Task Force recognised the importance of producing clear, concise and practical documents including: 1) a complete training programme, 2) guidelines for certification, 3) supporting educational materials, and 4) assessment criteria all of which form a strategy for project progression. Led by 13 representatives across Europe, each of the four project phases directly addresses the prerequisites vital to teach high-quality spirometry, laying the foundations to qualify health professionals to produce accurate and repeatable spirometric measurements to diagnose, treat and manage respiratory disease. The aim of the project was thus to produce a training programme to train basic quality spirometry competency. Unlike previous HERMES initiatives, the spirometry HERMES project was designed with the intention of encouraging competent individuals in all countries across Europe to deliver a standardised training package locally.

\section{PROJECT DEVELOPMENT}

Adopting the methodology tried and tested by previous HERMES projects, the consensus-based modified Delphi technique targeted a large number of pre-selected experts. This methodology surveyed expert opinions on each of the content items assembled by the Task Force. Results of the two webbased survey rounds assisted the Task Force in deciding the knowledge items to be included in the Training Programme, while also gathering qualitative feedback on proposed additional items and more generic comments on the project as a whole. 
Once the content items were approved, further rationale for training was developed by the Task Force panel, relying on their expert knowledge to assist in the completion of the manuscripts. The first two project phases are now complete and the following consensus based documents have been published [18].

\section{Phase I}

1) Part I Spirometry knowledge and skills.

2) Part II Knowledge and competence in measurement.

\section{Phase II}

3) Guidelines for the certification of ERS spirometry training programmes

Phase I documents present specifications for training and include the content, teaching methods and training duration, to train health professionals to become practically competent in spirometry testing. The documents indicate the completion of the first project phase.

The final document marks the Task Force efforts to utilise certification to apply standards as a basis of sustained quality assurance. Adopting the HERMES Criteria for Accreditation of European Training Centres as a model for development [19], the Task Force recommends guidelines structured and composed in six individual sections: 1) minimum components for training; 2) educational experience; 3) organisation of the training programme; 4) other organisational issues; 5) venue specifications; and 6) requirements for specific facilities.

Each of these six prescribed sections act as a checklist to facilitate a training programme in spirometry, and are essentially designed to establish optimal and achievable quality standards to contribute to effective surveillance and management of ERS European spirometry training programmes.

\section{DISCUSSION}

Any quality improvement strategy is fraught with complexities of change, inadequate resources and lack of urgency for new initiatives. The scale and scope of this mammoth undertaking is substantial and immersed in impending difficulty. How can one educational model be integrated across cultural, regional and national boundaries? Will practitioners and current leaders of spirometry become ambassadors to train and disseminate a European qualification in spirometry? How will the Task Force successfully guide the training programme from theory to practice? Success is highly dependent on a quality framework which enables facilitation at each and every barrier. The ERS training programme also needs to dovetail with other existing spirometry training courses in those countries where professional bodies already deliver courses.

\section{Dissemination of a spirometry training programme within Europe}

With the publication of the first two project phases, the HERMES Task Force takes their first step generating clear training documents using a simple model to allow for dissemination across medical settings. Although this Task Force has the unique advantage of representing 13 countries within Europe, project success requires coherence not only within the Task Force but across national societies and European training institutions. Managing diversity requires effective communication and documentation flexible enough to fit to a variety of cultures, and medical settings across Europe. Further to this, if the vision of the Task Force to disseminate a harmonised training programme across Europe is to be realised, translation of training documents to enable the ERS spirometry training programme to filter across medical settings around Europe must be considered. For the first time, a HERMES Task Force is confronted with the challenge of translation. Again, effective communication is essential to ensure that national respondents and other key stakeholders for the translation of documents are identified and supported.

\section{European spirometry trainers}

For a training programme in spirometry to circulate across Europe, offering the highest quality training and a successful and deliverable European qualification in spirometry, the role of the training programme director and training instructors are crucial. Entire project success is subject to involvement of spirometry trainers at all levels. A successful approach needs to consider the roles and responsibilities as well as offering the knowledge and skills for trainers in order to influence transformation in spirometry training processes. The crucial relationship between the governing body and European spirometry trainers is realised and the Task Force intends to develop this alliance, utilising a number of strategies including development of a "train-the-trainer" programme and support networks, ensuring all prerequisites required for this relationship to grow are managed.

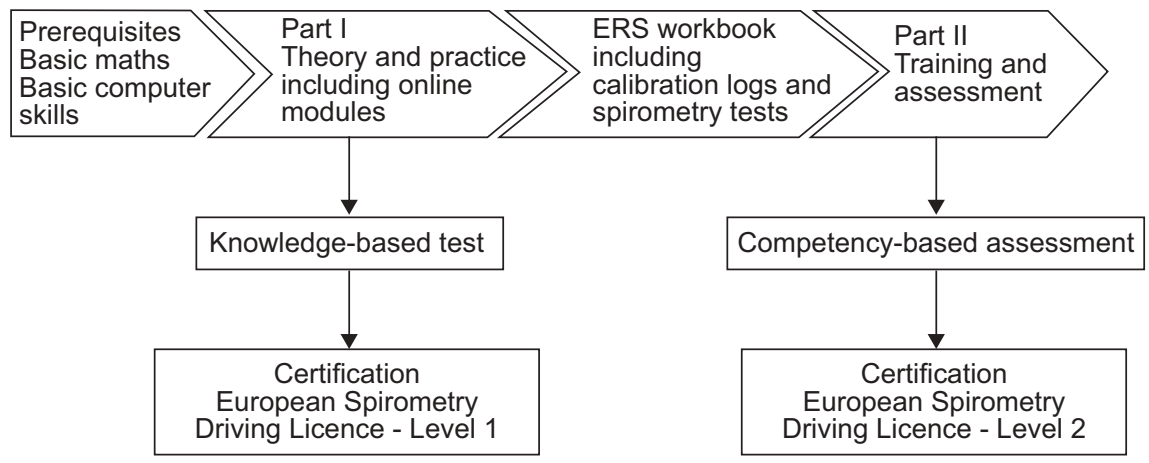

FIGURE 1. Schematic of the European Spirometry Driving Licence Task Force. 


\section{From theory to practice}

The overall objective of the HERMES spirometry training programme was to create consensus-based documents to train practically competent health professionals in spirometry, resulting in dissemination of the European Spirometry Driving Licence. Perhaps the greatest challenge encountered to date, generating cause for continuous debate, is the application of a training process to reach this project objective. To achieve and acquire competence necessitates not only instruction on theory and best practice, but also requires individuals to build their skills through personal effort. Therefore, it was quickly realised that to train and assess competence in spirometry testing, more was required than a 1-day training and assessment. To ensure that participants attending the course are practically competent at the end of training, a decision was taken that the training programme be divided into two distinct parts, to enable participants to practice and gather spirometric tests and complete an ERS workbook in spirometry between Part I and Part II.

To date, both training programmes for Part I and Part II training have now been published, as well as an ERS criteria for certification document. In articulating the process and activities required for each step, the framework provides a structure not only for the training of spirometry, but also to train a new generation of competent and qualified spirometry practitioners open to all healthcare workers who perform spirometry across Europe.

\section{NEXT STEPS}

Training programme capability requires effective documentation, trained spirometry trainers and clear process criteria and supporting documents (fig. 1). Every element must be supported by focused actions during project development. As the wheels for the project are now set in motion, the Task Force look towards establishing a train-the-trainer course outline with supporting educational materials to aid Europe's future spirometry champions. Training materials for participants attending the course will also be considered and developed as well as an ERS workbook in spirometry. In conjunction with this, further consideration will be placed on the training and certification process and thus complete a tangible spirometry training programme. Finally, the last challenge for the Task Force will be to produce criteria for assessment as well as knowledge based test and practical assessment to merit certification of the European Spirometry Driving Licence (fig. 1).

There is substantial evidence not only of the need to increase the use of spirometers as a diagnostic tool, but also to improve the accuracy of spirometric tests. Recognising education as the underpinning thread to enhance knowledge, skills and competencies, the HERMES spirometry project attempts to address these inadequacies and reform education and training of spirometry practice across Europe. It is intended that this article not simply be a broadcast to mark the completion of the first project steps rather that the significant potential for a harmonised training programme in spirometry is realised. At the most basic level, underlying a training programme outline in spirometry for trainers to follow offers a fundamental guide on how to deliver best practices in spirometry training. The true value of the project is embedded within its intended mission; to improve spirometry practice and positively impact on the lives of the millions of suffers of respiratory disease.

\section{STATEMENT OF INTEREST}

None declared.

\section{REFERENCES}

1 Bousquet J, Khaltaev N, eds. Global Surveillance, Prevention and Control of Chronic Respiratory Diseases: a Comprehensive Approach. Geneva, World Health Organization, 2007; WF140.

2 Bousquet J, Dahl R, Khaltaev N. Global alliance against chronic respiratory diseases. Eur Respir J 2007; 29: 233-239.

3 Bellia V, Pistelli R, Catalano F, et al. Quality control of spirometry in the elderly: The SA.R.A. Study: Salute Respiration nell'Anziano Respiratory Health in the Elderly. Am J Respir Crit Care Med 2000; 161: 1094-1100.

4 Yawn BP, Enright PL, Lemanske Jr, et al. Spirometry can be done in family physicians' offices and alters clinical decision in management of asthma and COPD. Chest 2007; 132: 1162-1168.

5 Cleland J, Mackenzie M, Small I, et al. Management of COPD in Primary Care in North-East Scotland. Scott Med J. 2006; 51: 10-14.

6 Cooper BG. Limitations to spirometry being performed in "the office". Chronic Respiratory Disease 2005; 2: 113-115.

7 Eaton T, Withy S, Garrett JE, et al. Spirometry in primary care practice: the importance of quality assurance and the impact of spirometry workshops. Chest 1999; 116; 416-423.

8 Schünemann HJ, Dorn J, Grant BJ, et al. Pulmonary function is a long-term predictor of mortality in the general population: 29-year follow-up of the Buffalo Health Study. Chest 2000:118; 656-664.

9 Cooper G, Troosters T, Burge G, et al. Allied Respiratory Professionals. Eur Respir J 2010; 36: 701-703.

10 Miller MR, Hankinson J, Brusasco V, et al. Standardisation of spirometry. Eur Respir J 2005; 26: 319-338.

11 Stoller JK, Orens DK, Hoisington E, et al. Bedside spirometry in a tertiary care hospital: the Cleveland clinic experience. Respir Care 2002; 47: 578-582.

12 Raghunath AS, Innes A, Norfolk M, et al. A comparison of primary care versus specialist diagnosis of airways disease. Thorax 2001; 56 : Suppl. 3, A86.

13 Loddenkemper R, Haslam PL, Séverin T, et al. HERMES: a European Core Syllabus in Respiratory Medicine. Breathe 2006; 3: 59-70.

14 Loddenkemper R, Séverin T, Eiselé J-L, et al. HERMES: good reasons for harmonising education and training in respiratory medicine. Eur Respir J 2006; 28: 470-471.

15 Gappa M, Noel JL, Séverin T, et al. Paediatric HERMES: a European syllabus in Paediatric Respiratory Medicine. Breathe 2009; 5: 237-247.

16 Gappa M, Paton J, Baraldi E, et al. Paediatric HERMES: update of the European Training Syllabus for Paediatric Respiratory Medicine. Eur Respir J 2009; 33: 464-465.

17 Gappa M, Noël JL, Séverin T, et al. European Curriculum Recommendations for Training in Paediatric Respiratory Medicine: one step further. Eur Respir J 2010; 36: 478-479.

18 Steenbruggen I, Mitchell S, Cooper BG, et al. Spirometry HERMES: Spirometry HERMES: A European training programme and qualification in spirometry practice. Breathe 2010; [DOI: 10.1183/ 20734735.026310].

19 Loddenkemper R, Séverin T, Mitchell S, et al. Adult HERMES: Criteria for Accreditation of ERS European Training Centres in Adult Respiratory Medicine. Breathe 2010; 7: 170-188. 